\title{
Membrane fluidity measurements in peripheral cells from Huntington's disease patients
}

\author{
G C BEVERSTOCK AND P L PEARSON \\ From the Department of Human Genetics, State University, Leiden, The Netherlands
}

SUMMARY The primary gene defect of Huntington's disease is believed to involve the membrane of some peripheral cells. The membrane fluidity of skin fibroblasts, erythrocytes and leucocytes was measured by fluorescence polarisation of a lipid specific probe, 1,6 diphenyl, 1,3,5 hexatriene. No significant difference between controls and Huntington's disease patients could be demonstrated.

Despite considerable research, the primary gene product of Huntington's disease (HD) has yet to be defined. The greatest problem is the inability to diagnose potential carriers of the disease, which, coupled with the fact that $50 \%$ of the offspring of an affected individual will contract the illness, makes it imperative that a reliable diagnostic technique be developed. The strategy of investigation into the disease has, however, changed dramatically in the last few years. Early studies involved primarily the pathology and biochemistry of the brain after death; however, since that time, the search has been extended to other peripheral tissues, based upon the concepts that in autosomal dominant diseases, the abnormal gene product is believed to be present (though not always completely expressed) in all cells of the body and secondly, that some neuropsychiatric disorders may be associated with membrane defects.

Menkes and Stein ${ }^{1}$ were among the first to claim differences in growth characteristics of Huntington fibroblasts. A review by Appel $^{2}$ described other studies which suggested that fibroblasts grew to greater density than normal and in addition appeared to be unusually sensitive to the lipid content of the medium. Tourian et $a l,{ }^{34}$ have suggested that HD fibroblasts are dependent upon glucosamine for cell survival in culture, display delayed adhesion to a plastic substrate and are also sensitive to excess glutamine. The increased growth rate and reduced contact inhibition of

Address for reprint requests Dr GC Beverstock, Department of Human Genetics, State University, Wassenaarseweg 72, 2333 AL, Leiden, The Netherlands.

Accepted 16 June 1981 cultured HD fibroblasts is also a feature of transformed cells, which is of interest, since cellular transformation has also been observed in the fibroblastic-type cells from brain tissue of individuals with certain degenerative diseases of the CNS, for example Kreutzfeldt-Jakob disease. ${ }^{5}$ If the transformation idea is true, however, it would be reasonable to suppose that changes would also be expressed at the cell membrane and indeed such changes have been claimed to occur in HD cells.

Electron spin resonance investigations by Butterfield and Markesbury, ${ }^{6}$ using a sulphydryl groupspecific probe MAL-6, have indicated an alteration in the protein organisational structure of $\mathrm{HD}$ erythrocyte membranes. In addition, an elevation in the membrane-bound $\mathrm{Na}+\mathrm{K}+$ ATPase enzyme activity, was also reported. ${ }^{7}$ However Pettegrew et $a l,{ }^{8}$ were unable to demonstrate any significant difference in levels of high energy phosphates in HD or controls, with a nuclear magnetic resonance (NMR) study, thus the significance of elevated $\mathrm{Na}+\mathrm{K}+$ ATPase, remains to be determined. Pettegrew et $a l^{910}$ reported that the cell membranes of both skin fibroblasts and erythrocytes from HD patients have different fluorescent characteristics from normals. They used the fluorescent probe 1,8-anilino naphthalene sulphonic acid (ANS) which when bound to specific membrane regions, gave a 30 -fold increase in intensity of excitation and emission spectra in HD cells, a shift in the emission maximum and an increase in polarisation of the emission spectrum. Continued subculture of HD fibroblasts to higher passages showed a change in these findings towards normal. 
In this paper we have examined the fluorescent polarisation characteristics of the cell membranes of skin fibroblasts, erythrocyte ghosts, and lymphocytes, from both HD and controls. We used the fluorescent probe 1,6 diphenyl, 1,3,5, hexatriene (DPH), in an attempt to establish whether there might be a difference in membrane fluidity between the cells of the two types of individual. DPH is one of the most frequently employed probes for measurements of fluorescence polarisation. A monochromatic, vertically polarised light source provides maximum excitation and the emission intensity is detected through an analyser orientated both parallel and perpendicular to the polarisation direction of the exciting light source. The degree of fluorescence polarisation can be represented by the formula:

$$
\mathbf{P}=\frac{\text { Iii-Ii }}{\text { Iii }+ \text { Ii }}
$$

Where Iii=Intensity of the fluorescent light, polarised parallel to the exciting beam.

Where Ii = Intensity of the fluorescent light, polarised perpendicular to the exciting beam.

The polarisation value $P$ is directly proportional to the microviscosity of the cell membranes, so that as $\mathbf{P}$ increases, the membranes become more rigid and less fluid. DPH itself is a molecule with an ellipsoidal form that resembles a rotating rod, with the advantage that the absorption and emission oscillators lie along the long axis of the fluorophore, hence only those rotations at $90^{\circ}$ to this axis will be effective in depolarising the fluorescence emission. DPH has an absorption maximum of $355 \mathrm{~nm}$ and in aqueous solutions, gives almost no fluorescence, but when in a lipid system, gives approximately a 1000 -fold increase in fluorescence. It is believed to be attached to the hydrocarbon region of the lipid layer in the cell membrane and to be almost evenly distributed. The probe has been widely used in membrane research to measure the membrane fluidity of normal and leukaemic lymphocytes of both humans and animals, ${ }^{11^{-15}}$ normal and transformed malignant fibroblasts, ${ }^{16-19}$ to demonstrate membrane interactions between contacting cells, ${ }^{20}$ to study variations in membrane fluidity during the cell cycle, ${ }^{21} 22$ and as an assay of phospholipid vesicles. ${ }^{23}$

\section{Materials and methods}

Cells

Fibroblasts: skin biopsies from eight adult and three juvenile HD patients and 11 normal controls were dissected into small pieces and put under sterile coverslips in Corning $38 \mathrm{~mm}$ Petri dishes. Hams F10 medium (Flow Labs) supplemented with $20 \%$ foetal bovine serum (Flow Labs), $20 \mathrm{mM}$ glutamine, hypoxanthine $136.1 \mathrm{mg} / 100 \mathrm{ml} \mathrm{PBS}$, penicillin 500000 $\mathrm{IU} / 1$ and streptomycin $500000 \mathrm{mcg} / 1$ was used as culture medium. The cells were incubated for 2 weeks at $37^{\circ} \mathrm{C}$ until a suitable outgrowth had occurred. The coverslips were then removed and placed with the cell layer uppermost in new Petri dishes and fresh medium added to all dishes. The medium was refreshed three times per week. When confluency was reached, after about 5-6 weeks, the fibroblasts were subcultured and plated out into $25 \mathrm{~cm}^{2}$ Falcon flasks (passage 1). The flasks were then incubated until confluent, again subcultured (passage 2) and plated out with a 1:2 split into $75 \mathrm{~cm}^{2}$ Falcon flasks and left until confluent (passage 3). Cells were grown for a further week, subcultured into glass Roux bottles and grown to confluence (passage 4). When confluent the cells were trypsinised, subdivided into $1 \mathrm{ml}$ glass ampoules with cryopreservative and stored in liquid $\mathrm{N}_{2}$ at passages varying from $4-7$.

\section{Staining details}

Fluorescence labelling of cells: the day before the experiment, three confluent flasks of fibroblasts per individual were washed once in warmed Earles medium and trypsinised with $\times 2$ EDTA trypsin for 10 minutes until all the cells were detached. The cells were then thoroughly resuspended with a Pasteur pipette until completely homogenous and the action of the enzyme stopped by the addition of $5 \mathrm{ml}$ fresh complete medium. The fibroblasts were centrifuged at $1200 \mathrm{rpm}$ for 10 minutes, the supernatant removed to $1 \mathrm{ml}$ and the cells resuspended in fresh Hams medium without serum, and put into siliconised glass tubes. The tubes were slowly rotated overnight at $37^{\circ} \mathrm{C}$ to reduce the possibility of fibroblast attachment to the walls of the test tubes, to maintain them in a rounded form and to allow the cells sufficient time to recover from any deleterious effects of the trypsin.

A stock solution of $2 \mathrm{mM}$ DPH (1,6,diphenyl, 1,3,5, hexatriene) Koch Light Laboratories, Colnbrook, England) was prepared in tetrahydrofuran. A working solution, was freshly prepared before each measuring session, that is $100 \mu \mathrm{l}$ DPH solution in tetrahydrofuran was added rapidly to vigorously stirred $100 \mathrm{ml}$ phosphate buffered saline and kept under bubbling nitrogen for 30 minutes to ensure complete evaporation of the tetrahydrofuran. The final solution was faintly opalescent and was checked for its fluorescence in the microviscometer before use. The fibroblasts were then washed twice in warmed PBS, stained with the DPH for 30 minutes at $37^{\circ} \mathrm{C}$, put into quartz measuring curvettes and the polarisation readings in triplicate were taken immediately.

Erythrocytes: peripheral blood was obtained by venepuncture from seven patients and six normal controls with EDTA as anticoagulant. "Ghost" cells were prepared by the method of Dodge et $a l^{24}$ and kept overnight in PBS at $4^{\circ} \mathrm{C}$. The next day, the cells were 
washed once in warm PBS, stained for 30 minutes at $37^{\circ} \mathrm{C}$, washed twice more and measured.

Leucocytes: $10 \mathrm{ml}$ of peripheral blood was obtained in heparin from two patients and two controls, mixed with Hanks balanced salt solution and $14 \mathrm{ml}$ FicollHypaque solution and allowed to stand. When settled cut, the suspension was centrifuged for 15 minutes at $1800 \mathrm{rpm}$ and the supernatant discarded. The buffy coat was removed and washed thoroughly with Hanks to ensure complete removal of the Ficoll. Cell samples were taken, stained with Turks Fluid and the cells counted in a Bürcher haemocytometer. The cells were stored overnight in RPMI 1640 medium and the next day washed once in PBS, stained for 30 minutes with $\mathrm{DH}$, washed twice more and measured.

\section{Fluorescence measurements}

Fluorescence polarisation and intensity were measured in an instrument especially adapted from a Zeiss PMQ-2 spectrophotometer. Light from a 100W mercury vapour lamp of excitation $365 \mathrm{~nm}$, was passed through a rotatable sheet polariser. The fluorescence intensity was measured simultaneously both parallel and perpendicular to the exciting beam by photomultiplier tubes, after passing through an aqueous $2 \mathrm{M} \mathrm{NaNO}{ }_{2}$ solution as cutoff filter for all wavelengths of less than $390 \mathrm{~nm}$. The temperature was controlled by thermoelectric elements (Cambion Model 3959-01, Cambridge Thermionic Corp, Cambridge, Mass) and held to $\pm 0.1^{\circ} \mathrm{C}$ over the range $0^{\circ} \mathrm{C}-40^{\circ} \mathrm{C}$. Polarisation values were calculated by the formula previously mentioned.

\section{Results}

The mean polarisation values obtained for Huntington fibroblasts (table 1), varied between $0 \cdot 24$ $0 \cdot 29$ and for control cells between $0 \cdot 25-0 \cdot 28$, with an overlap of values among all groups. No signifi- cant difference in mean values between any matched pair of patient/control samples was detectable, although the HD fibroblasts showed a greater range of values in polarisation values, ie $0.2227-0.3023$, compared with $0.2447-0.2831$ for controls. The polarisation values for cultures of high passage number, did not differ significantly from those at lower passage for both patient and control groups. In so far as the age of biopsy donors was concerned, there appeared to be little difference in polarisation values between the five juvenile cases and the adult cases.

The adult donors were all within a restricted age range of 30-50 years; older individuals were not used because of the possible variation in growth characteristics of senescent skin fibroblasts. Fibroblast cell lines from two patients and two controls were also obtained from the Cell Repository, Camden, New Jersey, matched for sex and age, to act as reference samples. Again, no appreciable difference was observed between cultures established from our biopsies and those obtained from Camden. Inspection of standard deviation (SD) values (tables 1 and 2), suggests a greater heterogeneity in the HD population than in normals. This was confirmed by application of the variance ratio test which showed that for $\stackrel{\mathbb{Q}}{\varrho}$ both fibroblasts and erythrocyte ghost cells, the calculated $\mathrm{F}$ value approximated to a $5 \%$ significance difference.

Fibroblast suspensions in triplicate were prepared from confluent Falcon flasks as described in Materials and methods and the polarisation values observed and measured on three different occasions over a 2 -week period (table 3). It would appear that the polarisation values vary by a fac-

Table 1 Polarisation $(P)$ values of human fibroblasts in suspension with the fluorescent probe 1,6Diphenyl, $1,3,5$, Hexatriene $(D P H)$

\begin{tabular}{|c|c|c|c|c|c|c|c|c|c|c|c|}
\hline \multicolumn{6}{|c|}{ Huntington patients } & \multicolumn{6}{|l|}{ Controls } \\
\hline Name & $\begin{array}{l}\text { Age } \\
\text { (yr) }\end{array}$ & $\operatorname{Sex}$ & $\begin{array}{l}\text { Passage } \\
\text { number }\end{array}$ & $(P)$ & $S D$ & Name & $\begin{array}{l}\text { Age } \\
(y r)\end{array}$ & $\operatorname{Sex}$ & $\begin{array}{l}\text { Passage } \\
\text { number }\end{array}$ & $(P)$ & $S D$ \\
\hline $\begin{array}{l}\text { JHN } \\
\text { HDH } \\
\text { JVH } \\
\text { MH } \\
\text { MIM } \\
\text { SEB } \\
\text { RH } \\
\text { JWH } \\
\text { MM } \\
\text { GM-1170 } \\
\text { GM-1085 }\end{array}$ & $\begin{array}{r}30 \\
43 \\
40 \\
11 \\
47 \\
36 \\
6 \\
32 \\
13 \\
35 \\
44\end{array}$ & $\begin{array}{l}\mathbf{M} \\
\mathbf{F} \\
\mathbf{M} \\
\mathbf{F} \\
\mathbf{M} \\
\mathbf{F} \\
\mathbf{M} \\
\mathbf{M} \\
\mathbf{M} \\
\mathbf{F} \\
\mathbf{M}\end{array}$ & $\begin{array}{r}10 \\
7 \\
7 \\
4 \\
4 \\
4 \\
4 \\
3 \\
10 \\
9 \\
9\end{array}$ & $\begin{array}{l}0 \cdot 2467 \\
0 \cdot 2586 \\
0 \cdot 2544 \\
0 \cdot 2907 \\
0 \cdot 2701 \\
0 \cdot 2456 \\
0 \cdot 2409 \\
0 \cdot 2727 \\
0 \cdot 2459 \\
0 \cdot 2913 \\
0 \cdot 2709\end{array}$ & $\begin{array}{l}0.0055 \\
0.0047 \\
0.0176 \\
0.0044 \\
0.0065 \\
0.0060 \\
0.0040 \\
0.0039 \\
0.0056 \\
0.0084 \\
0.0029\end{array}$ & $\begin{array}{l}\text { FN } \\
\text { AD } \\
\text { VAH } \\
\text { SB } \\
\text { G } \\
\text { MJB } \\
\text { LT } \\
\text { GJB } \\
\text { SB } \\
\text { GM-2153 } \\
\text { GM-2169 }\end{array}$ & $\begin{array}{r}28 \\
43 \\
39 \\
13 \\
42 \\
36 \\
9 \\
28 \\
13 \\
40 \\
52\end{array}$ & $\begin{array}{l}\mathbf{F} \\
\mathbf{M} \\
\mathbf{F} \\
\mathbf{F} \\
\mathbf{M} \\
\mathbf{F} \\
\mathbf{F} \\
\mathbf{F} \\
\mathbf{F} \\
\mathbf{F} \\
\mathbf{M}\end{array}$ & $\begin{array}{r}10 \\
7 \\
7 \\
4 \\
4 \\
4 \\
4 \\
13 \\
4 \\
9 \\
9\end{array}$ & $\begin{array}{l}0.2533 \\
0.2718 \\
0 \cdot 2571 \\
0.2800 \\
0.2591 \\
0 \cdot 2600 \\
0 \cdot 2635 \\
0 \cdot 2558 \\
0 \cdot 2800 \\
0 \cdot 2693 \\
0 \cdot 2697\end{array}$ & $\begin{array}{l}0.0109 \\
0.0035 \\
0.0178 \\
0.0054 \\
0.0087 \\
0.0042 \\
0.0072 \\
0.0041 \\
0.0054 \\
0.0046 \\
0.0089\end{array}$ \\
\hline \multicolumn{6}{|c|}{$\begin{array}{l}\text { Total no patients }=11 \\
\text { Mean of all } P \text { values }(\bar{x})=0.2625 \text {. } \\
\text { Standard error of mean }=0.0179 \text {. } \\
\text { Variance ratio: } P=0.05 \text { where } F=3 \text {. }\end{array}$} & \multicolumn{6}{|c|}{$\begin{array}{l}\text { Total no controls }=10 \text {. } \\
\text { Mean of all } P \text { values }(\bar{x})=0 \cdot 2639 \text {. } \\
\text { Standard error of mean }=0.0085 \text {. }\end{array}$} \\
\hline
\end{tabular}


Table 2 Polarisation values of erythrocyte ghosts with the fluorescent probe 1,6,Diphenyl, 1,3,5,Hexatriene

\begin{tabular}{|c|c|c|c|c|c|c|c|c|c|}
\hline \multicolumn{5}{|c|}{ Huntington patients } & \multicolumn{5}{|c|}{ Controls } \\
\hline Name & $\begin{array}{l}\text { Age } \\
(y r)\end{array}$ & $\operatorname{Sex}$ & $P$ value & $S D$ & Name & $\begin{array}{c}\text { Age } \\
(y r)\end{array}$ & Sex & $P$ value & $S D$ \\
\hline $\begin{array}{l}\text { SEB } \\
\text { LB } \\
\text { HDH } \\
\text { EJS } \\
\text { JHGK } \\
\text { WPvL } \\
\text { DK }\end{array}$ & $\begin{array}{l}29 \\
28 \\
44 \\
29 \\
34 \\
65 \\
58\end{array}$ & $\begin{array}{l}\mathbf{F} \\
\mathbf{M} \\
\mathbf{F} \\
\mathbf{F} \\
\mathbf{F} \\
\mathbf{F} \\
\mathbf{M}\end{array}$ & $\begin{array}{l}0 \cdot 3175 \\
0 \cdot 3340 \\
0 \cdot 3126 \\
0 \cdot 3310 \\
0 \cdot 3024 \\
0 \cdot 3216 \\
0 \cdot 3200\end{array}$ & $\begin{array}{l}0.0084 \\
0.0138 \\
0.0124 \\
0.0015 \\
0.0015 \\
0.0043 \\
0.0048\end{array}$ & $\begin{array}{l}\text { MJB } \\
\text { AD } \\
\text { WE } \\
\text { GG } \\
\text { LW } \\
\text { LW }\end{array}$ & $\begin{array}{l}37 \\
44 \\
28 \\
42 \\
52 \\
52\end{array}$ & $\begin{array}{l}\mathbf{M} \\
\mathbf{M} \\
\mathbf{M} \\
\mathbf{M} \\
\mathbf{M} \\
\mathbf{M}\end{array}$ & $\begin{array}{l}0 \cdot 3222 \\
\overline{0} \\
0 \cdot 3142 \\
0 \cdot 3173 \\
0 \cdot 3102 \\
0 \cdot 3257 \\
0 \cdot 3126\end{array}$ & $\begin{array}{l}0.0060 \\
0.0047 \\
0.0014 \\
0.0014 \\
0.0060 \\
0.0045\end{array}$ \\
\hline
\end{tabular}

Total no patients $=7$.

Mean of all $P$ values $(\bar{x})=0 \cdot 3199$.

Standard error of mean $=0.0107$.

Variance ratio: $\mathbf{P}=0.05$ where $F=3$.

Total no controls $=6$.

Mean of all $P$ values $(\bar{x})=0.3170$.

Standard error of mean $=0.0059$.

Table 3 Repeated polarisation measurements of fibroblasts with DPH

\begin{tabular}{lllllll}
\hline Name & $\begin{array}{l}\text { Age } \\
(y r)\end{array}$ & Sex & $\begin{array}{l}\text { Original } \\
\text { measurement }\end{array}$ & 1st repeat & 3rd repeat \\
\hline MH & 12 & F & $0 \cdot 29 \pm 0.004$ & $0.25 \pm 0.005$ & $0.23 \pm 0.0045$ \\
RH & 7 & M & $0.24 \pm 0.004$ & $0.246 \pm 0.005$ & 0.21 \\
MM & 15 & M & $0 \cdot 24 \pm 0.005$ & 0.27 & $0.214 \pm 0.005$ & 0.005 \\
1170 & 34 & F & $0.29 \pm 0.008$ & $0.242 \pm 0.0084$ & $0.236 \pm 0.005$ & $0.254 \pm 0.005$ \\
\hline
\end{tabular}

tor of +0.05 , when measured at different times. This needs to be taken into account when assessing the significance of differences between cell types. Cell viability tests, using trypan blue, showed the fibroblasts to have a viability of $90-95 \%$ after the overnight rotation in the siliconised tubes.

Table 2 shows the polarisation values obtained for the erythrocyte ghosts, which were higher than those from fibroblasts and within closer limits, probably due to the greater homogeneity of the red cells. However, no significant difference was observed between Huntington cell and normals, nor between age or sex of the individuals. Polarisation values for leucocytes showed no discernible difference between Huntington patients and controls (see table 4).

Table 4 Polarisation values of leucocytes with the fluorescent probe 1,6,Diphenyl, 1,3,5,Hexatriene

\begin{tabular}{llllll}
\hline Name & $\begin{array}{l}\text { Age } \\
(y r)\end{array}$ & Sex & Type & P value & $\begin{array}{l}\text { Cell counts } \\
\times 10 \% / m l\end{array}$ \\
\hline LW & 52 & M & Control & $0 \cdot 28$ & $2 \cdot 2$ \\
MK & 55 & F & Control & $0 \cdot 28$ & $2 \cdot 5$ \\
DK & 58 & M & HD & $0 \cdot 27$ & $1 \cdot 96$ \\
WPL & 65 & F & HD & $0 \cdot 28$ & $2 \cdot 3$ \\
\hline
\end{tabular}

\section{Discussion}

There is evidence to support the idea of a general membrane defect in Huntington's disease. ${ }^{2-4}$ 6-10 The fluorescent probe DPH has been widely used in the study of the dynamics of the hydrocarbon region of the surface membrane lipid bilayer. ${ }^{11} 25^{-28}$ We have used DPH to investigate the membrane fluidity of the cell membranes of fibroblasts, leucocytes and "ghost" erythrocytes from both Huntington patients and normal controls. No significant difference was found between patient and normal controls in any of the different cell types used, a finding confirmed by Kraus and Williams for lymphocytes (unpublished) and by Abood and Butler $^{29}$ for erythrocyte ghost cells. The magnitude of our measurements corresponds with the findings obtained by other investigators on similar cell types.

The majority of fibroblast cultures used were in early passage ( 3 to 4$)$ at the time of measurement and the remainder, at late passage ( 7 to 13 ) did not appear to differ significantly in their polarisation values. Hence passage number would not seem to be a critical factor, also confirmed by Haggerty et al. ${ }^{30}$ In contrast, Pettegrew et al, ${ }^{9} 10$ found that the corrected spectra of Huntington fibroblasts after staining with the fluorescent probe 1,8 ,anilosulphonic acid, were indeed grossly different in excitation and emission intensity at early passage but this difference was found to have disappeared by passage 10 .

Independently established fibroblast cultures from the Camden Cell Repository were found to have similar polarisation values and growth characteristics to the cultures established in our laboratory.

The results shown in this study are expressed in 
terms of polarisation values only, which are in turn, directly proportional to viscosity, that is the higher the $\mathbf{P}$ value, the higher viscosity, hence the lower the fluidity of the membrane and vice versa. No depolarisation corrections were made to the polarisation values we obtained because the intensity of the fluorescent signal was high enough to make the effects of light scattering or background values, negligible. ${ }^{21}$ We have measured fluorescent anisotropy of skin fibroblasts in suspension, subsequent to trypsinisation, in preference to measurement of confluent cells grown on suitably sized coverslips, as advocated by other authors. ${ }^{910} 21$ Our pilot studies showed that after 3-7 days in culture, both confluent and nonconfluent fibroblasts on glass, produced extremely low fluorescence polarisation values in comparison to suspension cultures. The glass coverslips, when inserted into the quartz cuveties of the spectrophotometer, were found to be covered with a milky white deposit which was sufficiently turbid to prevent most of the fluorescent signal reaching the photomultiplier tubes. The explanation of this observation is not known.

The trypsinisation of confluent fibroblasts was found to provide a more homogenous suspension with less debris and a greater cell yield, than that obtained by scraping the cells with a rubber policeman. However, de Laat et al, ${ }^{21}$ suggested that trypsin treatment increased the microviscosity of the cell membrane whereas Shinitzky and Inbar, ${ }^{11}$ Inbar et $a l,{ }^{16}$ and Levanon et al ${ }^{31}$ could find no such difference in polarisation after the action of this enzyme.

In conclusion, fluorescent polarisation measurements of the plasma membranes of skin fibroblasts, red cells and leucocytes showed no significant difference between Huntington patients and control samples. They are therefore concordant with the opinion of Butterfield et $a l^{6} 7$ and Abood and Butler, ${ }^{29}$ that alteration in the lipid fraction of the membrane is not the genetic defect involved in the disease. It is possible that the greater heterogeneity demonstrated by HD patients may be caused by extraneous effects such as drug therapy, weight loss etc. The uncertainty surrounding the exact location of the fluorescent probe in the cell membrane, does not necessarily invalidate our results since Andersen, ${ }^{25}$ has suggested that an alternative way of using fluorescent probes is to regard the measured properties merely as diagnostics for observing membrane transitions, even though details of the actual probe location within the membrane are not known. Further work is in progress to examine the protein configuration of membranes from erythrocyte ghosts in Huntington's disease, using the electron spin resonance technique described by Butterfield and Markesbury. ${ }^{6}$

The authors gratefully acknowledge the help of Dr S de Laat, Utrecht, for use of the microviscometer, Professor Dr G Bruyn and Professor Dr LN Went for biopsy material.

\section{References}

1 Menkes JH, Stein N. Fibroblast cultures in Huntington's disease. $N$ Engl J Med 1973; 288: 856-7.

2 Appel SH. Membrane defects in Huntington's Disease. Adv Neurol 1979; vol 23: 387-96. In: Chase TN, ed. Huntingtons Disease. New York: Raven Press.

3 Tourian A, Hung WY. Glucosamine dependence of Huntington's Chorea fibroblasts in culture. Biochem Biophys Res Comm 1977; 76(2):345-53.

4 Tourian A, Hung WY. Membrane abnormalities of Huntington's Chorea fibroblasts in culture. Biochem Biophys Res Comm 1977; 78(4):1296-303.

5 Hooks J, Gibbs CJ, Chopra H, Lewis M, Gajdusek DC. Spontaneous transformation of human brain cells grown in vitro and description of associated virus particles. Science 1972; 176: 1420-2.

6 Butterfield DA, Markesbury WR. Erythrocyte membrane alterations in Huntington's disease. Adv Neurol 1979; vol 23: 397-408. In: Chase TN, ed. Huntington's Disease. New York: Raven Press.

7 Butterfield DA, Oeswein JW, Prunty MJ, Hisle $\mathrm{KC}$, Markesbury WR. Increased sodium plus potassium adenotriphosphatase activity in erythrocyte membranes in Huntington's disease. Ann Neurol 1978; 4:60-2.

8 Pettegrew JW, Glonek T, Stewart RM. Phosphorous-31 nuclear magnetic resonance ( ${ }^{31} \mathrm{P}$ NMR) studies in blood in Huntington's disease. Ann Neurol 1979; 6:164.

9 Pettegrew JW, Nichols JS, Stewart RM. Fluorescence spectroscopy on Huntington fibroblasts. J Neurochem 1979; 33:905-11.

10 Pettegrew JW, Nichols JS, Stewart RM. Studies of the fluorescence of fibroblasts from Huntingtons' disease: evidence of a membrane abnormality. N Engl J Med 1979; 300:678.

11 Shinitzky $\mathbf{M}$, Inbar $\mathbf{M}$. Difference in microviscosity induced by different cholesterol levels in the surface membrane lipid layer of normal lymphocytes and malignant lymphoma cells. $J$ Mol Biol 1974; 85:603-15.

12 Esko JD, Gilmore JR, Glaser M. Use of a fluorescent probe to determine the viscosity of LM cell membranes with altered phospholipid compositions. Biochem 1977; 16(9):1881-90. 
13 Inbar M, Shinitzky M, Sachs L. Microviscosity in the surface membrane lipid layer of intact normal lymphocytes and leukaemic cells. FEBS Letters 1974; 38(3):268-70.

14 Petitou M, Tuy F, Rosenfeld C, Mishal Z, et al. Decreased microviscosity of membrane lipids in leukaemic cells. 2 possible mechanisms. Proc Nat Acad Sci 1978; 75(5):2306.

15 Yanovich S, Harris Kathleen, Sallan SE, Schlossman SF, Inbar M. Dynamic parameters of membrane lipids in normal and leukaemic human lymphocytes isolated from peripheral blood and bone marrow. Cancer Res 1978; 38:4654-61.

16 Inbar M, Yuli I, Raz A. Contact-mediated changes in the fluidity of membrane lipids in normal and malignant transformed mammalian fibroblasts. Exp Cell Res 1977; 105:325-35.

17 Pessin JE, Salter DW, Glaser M. Use of a fluorescent probe to compare the plasma membrane properties in normal and transformed cells. Evaluation of the interference by triacylgycerols and alkyldiacylglycerols. Biochem 1978; 17(10: 1997.

18 Nicolau C, Hildenbrand K, Reimann Alice, Johnson Sheena M, Vaheri A, Friis RR. Membrane lipid dynamics and density dependent growth control in normal and transformed avian cells. Exp Cell Res 1978; 113:63-73.

19 Fuchs P, Parola A, Robbins PW, Blout ER. Fluorescence polarisation and viscosities of membrane lipids of 3T3 cells. Proc Nat Acad Sci 1975; 72(9):3351-4.

20 Collard JG, de Wildt A, Inbar M. Translocation of a fluorescent lipid probe between contacting cells. FEBS Letters 1978; 90:24-8.

21 de Laat SW, vd Saag PT, Shinitzky M. Microviscosity modulation during the cell cycle of neuroblastoma cells. Proc Nat Acad Sci 1977; 74(10):4458-61.
22 Obrenovitch Angèle, Sené C, Nègre MarieThérèse, Monsigny $M$. Fluorescence polarisation of 1,6,-diphenyl-1,3,5-hexatriene embedded in membranes of mouse leukaemic L1210 cells during the cell cycle. FEBS Letters 1978; 88: 187-9.

23 London E, Feigenson GW. A convenient and sensitive fluorescence assay for phospholipid vesicles using diphenyl hexatriene. Analyt Biochem 1978; 88:203-11.

24 Dodge JT, Mitchell Carolyn, Hanahan DJ. The preparation and chemical characteristics of haemoglobin-free ghosts of human erythrocytes. Arch Biochem 1962; 100:119-30.

25 Andersen HC. Probes of membrane structure. Ann Rev Biochem 1978; 47:359-83.

26 Radda GK, Vanderkooi Jane. Can fluorescent probes tell us anything about membranes? Biochim Biophys Acta 1972; 265:509-49.

27 Azzi A. The application of fluorescent probes in membrane studies. $Q$ Rev Biophys 1975; 8:237316.

28 Singer SJ. The molecular organisation of membranes. Ann Rev Biochem 1974; 43:805-33.

29 Abood Mary E, Butler Madeline. Membrane fluidity and fatty acid composition of phospholipids in erythrocyte membranes of patients with Huntington's disease. J Neurosc Res 1979; 4: 183-7.

30 Haggerty DF, Kalra VK, Popjak G, Reynolds EE, Chiappell F. Fluorescence-polarisation measurements on normal and mutant human skin fibroblasts. Arch Biochem Biophys 1978; 189: 51-62.

31 Levanon A, Kohn A, Inbar M. Increase in lipid fluidity of cellular membranes induced by adsorption of RNA and DNA virions. J Virol 1977; 22:353-60. 